ERC Working Papers in Economics 18/04

February / 2018

\title{
SMOOTH BREAKS AND NONLINEAR MEAN REVERSION IN REAL INTEREST PARITY: EVIDENCE FROM EAST ASIAN COUNTRIES
}

\author{
Abdullah Gülcü \\ Department of Economics, Middle East Technical University, Ankara, Turkey \\ E-mail: agulcu@ metu.edu.tr \\ Phone: + (90) 3122103090
}

\section{Dilem Yıldırım}

Department of Economics, Middle East Technical University, Ankara, Turkey E-mail: dilem@metu.edu.tr

Phone: +(90) 3122102019 


\title{
SMOOTH BREAKS AND NONLINEAR MEAN REVERSION IN REAL INTEREST PARITY: EVIDENCE FROM EAST ASIAN COUNTRIES
}

\begin{abstract}
Abdullah GULCU
Department of Economics, Middle East Technical University, 06531, Ankara, TURKEY Email: agulcu@metu.edu.tr, Phone: +90 312210 3090, Fax: +(90) 3122107964
\end{abstract}

\section{Dilem YILDIRIM}

Department of Economics, Middle East Technical University, 06531, Ankara, TURKEY Email: dilem@metu.edu.tr, Phone: +90 312210 2019, Fax: +(90) 3122107964

Corresponding Author: Dilem YILDIRIM, dilem@ metu.edu.tr, phone: +90 3122102019 


\title{
SMOOTH BREAKS AND NONLINEAR MEAN REVERSION IN REAL INTEREST PARITY: EVIDENCE FROM EAST ASIAN COUNTRIES
}

\begin{abstract}
This study aims to explore the empirical validity of the real interest rate parity (RIP) hypothesis for East Asian countries using Japan as the base country. To this end, we employ the recently proposed unit root tests of Christopoulos and Leon-Ledesma (2010) that account for both multiple smooth structural breaks of unknown form and nonlinear mean reversion in the series. Our empirical results uncover overwhelming evidences in favor of the RIP hypothesis for the whole countries in our sample. More specifically, through a Fourier approximation, it is observed that all real interest rate differentials display a mean reverting behavior around an infrequently smooth-breaking mean, with the breaks being in accordance with the financial reforms and economic crises witnessed by the countries. Moreover, the degree of mean reversion appears to vary nonlinearly with the size of real interest rate appreciations and depreciations.
\end{abstract}

Keywords: Real Interest Rate Parity, Financial Integration, Nonlinearity, Smooth Structural Breaks, East Asian Countries

JEL classification numbers: C22, E40, F36, F40, G01 


\section{Introduction}

For the last three decades, many countries have made great effort to enable free movement of capital and goods among nations. Especially with the collapse of Bretton Wood Era, international connectedness of capital and goods markets has accelerated significantly. Countries have liberalized their financial and real sectors by eliminating the barriers towards the movements of capital and goods across countries, deregulating their financial sectors and signing trade agreement to lower the transaction cost of the goods. Moreover, with technological advances, which led to further reductions in information and trading costs, economies became more integrated. Real interest rate parity (RIP), which is based on the validity of uncovered interest rate parity (UIP) and purchasing power parity (PPP) implying integration in assets and goods markets, respectively, is an effective measure of overall economic integration. According to the RIP hypothesis real interest rates across countries must be equal provided that investors have rational expectations and arbitrage forces are free to act in the goods and assets markets. In other words, assets with identical risks should bring the same expected return across the world as long as real and financial market efficiency is ensured.

Empirical validity of the RIP hypothesis is quite important for policymakers, economists and investors. If RIP holds, domestic real interest rates will be strongly linked to the foreign or world real rate and cannot differentiate much from it. Given the importance of real interest rates for investment and saving decisions, the validity of RIP leads monetary authorities to have limited influence on real macroeconomic variables through the interest rate channel. This is, of course, more prominent for small economies with low power to affect their domestic sector through monetary policies. The RIP hypothesis is also crucial to our understanding of international macroeconomics as various exchange rate and open economy models, including the model developed by Frenkel (1976) and Mussa (1982), are based on the validity of RIP. From the point of view of investors, the validity of RIP is important not only because it implies equalization of real interest rates across countries but also it could be used to simplify hedging practices for financial investment and international portfolio diversification decisions.

Given that RIP implies mean reversion of the real interest rate differentials (rids) or their tendency to converge on a long-run equilibrium level in response to any short-run disturbance, its empirical validity is examined in the literature mainly through cointegration and unit root tests. Although there is an extensive literature concerning the validity of RIP, the 
evidence is mixed, with different researchers proposing different conclusions depending on the period and countries studied ${ }^{1}$. Many studies examine the empirical validity of the RIP hypothesis by using standard unit root and cointegration testing procedures or their panel data variants in a linear context. In this sense, empirical validity of the RIP hypothesis is supported for a number of countries in studies by Al-Awad and Goodwin (1998) for G10 countries; Phylaktis (1999) for a group of Pacific-Basin countries; Yamada (2002) for US, Japan and UK; and Lee (2002) for a number of economic blocs such as Asia-Pacific, Europe and North America., Jenkins and Madzharova (2008) and Singh and Banarjee (2006), on the other hand, fail to support RIP for Asian countries, European Union (EU) countries and emerging economies, respectively. Moreover, empirical evidences of Holmes (2002) for the EU, Bagdatoglou and Kontonikas (2011) for G7 countries and Ji and Kim (2009) for Pacific-Basin countries are supportive of RIP only over some specific periods. Controversial results were ascribed to the low power of the standard tests used in these studies. Subsequently, the literature has developed mainly in two directions to address the power problem through the use of more sophisticated testing procedures.

In this sense, the first strand focuses on the presence of possible structural breaks in real interest rates due to economic and political changes. It is known that conventional testing procedures perform relatively well when applied to time series being exposed to no structural breaks. However, as indicated by Perron (1989), conventional inferences might be misleading and seriously biased in the presence of structural breaks. Consequently, many recent empirical studies, including Lai (2004), Maveyraud - Tricoire and Raus (2009), Bagdatoglou and Kontonikas (2011) and Camarero et al. (2010), Magonis and Tsopanakis (2013), utilize the testing procedures that allow for structural breaks and propose more supportive evidence for the validity of the RIP hypothesis.

The second strand of the literature questions one of the strong assumptions of the earlier studies, which is linearity in rids. In fact, many factors like transaction costs, asymmetric information and the existence of limits to speculation can induce a nonlinear, asymmetric structure in rids. As proposed by Dumas (1992) and Sercu et al. (1995) and underlined more recently by Mancuso et al. (2003), existence of transaction costs both in goods and assets markets might cause nonlinearities, with different dynamic properties depending on the presence of arbitrage opportunities. More specifically, transaction costs create a neural band, within which rids may follow a (near) random walk process, as arbitrage

${ }^{1}$ See Neely and Rapach (2008), and Sirichand et al. (2015) for an extensive review of the RIP literature. 
is not large enough to cover transaction costs. This is especially the case for contractual arrangements, which require assets to be held for a certain predetermined period and therefore it becomes costly to benefit from profits. However, outside of the band, arbitrage becomes profitable and this encourages a tendency toward parity for rids. Moreover, as underlined by Ferreira and Leon-Ledesma (2007), due to the existence of asymmetric information in international credit markets, risk perceptions of investors will vary with changes in interest rates and this will breed an asymmetric structure in rids. The nonlinear behaviour can also be attributed to the limits to speculation hypothesis. This hypothesis states that financial market players choose a strategy if its expected excess return per unit of risk (Sharpe ratio) is higher than that of alternative trading strategies. This argument effectively creates a band of inaction where the deviation from RIP is not eliminated until it generates Sharpe ratios that are high enough to attract speculative capital away from alternative trading strategies (Lyons, 2001; Sarno et al., 2006).

Accordingly, a growing literature has emerged to address empirical validity of the RIP hypothesis within a nonlinear context. In this sense, Cooray (2009), Holmes and Maghrebi (2004), Ferreira and Leon-Ledesma (2007), Sekioua (2008), Sarpota (2009), Cuestas and Harrison (2010), Baharumshah et al. (2009), among others, utilize nonlinear cointegration and unit root tests to investigate the empirical validity of RIP for a broad range of developing and developed countries. Compared to the previous studies, these studies almost uniformly reveal that evidence in favor of stationarity of rids markedly strengthens when nonlinearities in rids are explicitly accommodated.

Although there are a plenty of studies available on the empirical validity of the RIP hypothesis and it is growing with the availability of more sophisticated testing procedures, the existing literature has largely focused on developed and industrialized countries. The literature has overlooked the financial integration especially in transition economies, with studies analyzing the RIP hypothesis for transition economies being rather limited. In this sense, our study aims to investigate the empirical validity of the RIP hypothesis for East Asian countries, China, Hong Kong, South Korea, Indonesia, Malaysia, Philippines, Singapore and Thailand by taking Japan as the base country. East Asian economies began their financial integration in 1980s. During the past three decades, following almost the same pattern, they have experienced fundamental changes towards a market-oriented economy by progressively liberalizing their domestic financial systems and removing obstacles to capital mobility. Although, these countries have witnessed some financial crisis, like Asian crisis in 1997 and the subprime mortgage crisis in 2008, during this time span, they managed to drive 
their economies into a more sound and stable pattern with revised financial policies and implementation of more systematic regulations. All implemented liberalization steps have strengthened financial and real sectors of East Asian countries and boosted the financial market integration realized in these countries, which provides a good platform to test the RIP hypothesis.

When examining the RIP literature for East Asian countries, it appears that studies methodologically focus on the existence of possible structural breaks (Chang et al. (2012), Baharumshah et al. (2013) and Liu et al. (2013)) and nonlinearity in rids (Holmes and Maghrebi (2004), Baharumshah et al. (2008), Baharumshah et al. (2010) and Su et al. (2012)). The general method to account for breaks is to approximate them through endogenously determined dummy variables. The only exception to this is the study of Liu et al. (2013), who allow for smooth and gradual structural breaks by means of a Fourier function. Holmes and Maghrebi (2004), Baharumshah et al. (2008) and Baharumshah et al. (2010), on the other hand, consider the potential nonlinear mean reversion in rids and employ nonlinear unit root tests to test the RIP hypothesis. Being in line with the existing RIP literature, all these studies, however, ignore the possible interaction between existence of structural breaks and nonlinearity in rids and treat both problems separately. In fact, it is quite plausible that the policies or events that led to structural breaks in rids may change the equilibrium level, while mean reversion toward this new level may still follow a nonlinear path due to the potential reasons discussed above (Papell, 2002). If this is the case, accounting for either structural breaks or nonlinearity separately, might produce misleading and biased inferences.

This study aims to contribute to the RIP literature by addressing this possible interaction. As such, we utilize the recently proposed unit root tests of Christopoulos and Leon-Ledesma (2010), which allow for both multiple smooth breaks and nonlinear mean reversion in rids. The unit root tests developed by Christopoulos and Leon-Ledesma (2010) account for the fact that structural changes generally take a period of time to effect in an economy and take the form of large swings that cannot be captured well by dummy variables, which suggest sharp and sudden changes. Structural breaks are therefore modeled as a smooth process via flexible Fourier functions. Nonlinearity, on the other hand, is modeled by an exponential smooth transition autoregressive (ESTAR) process, which is designed specifically on the basis of the no arbitrage versus profitable arbitrage argument of Dumas (1992) and Sercu et al. (1995).

Roughly, our empirical findings reveal conclusive evidences in favor of the RIP hypothesis for the whole countries in our sample. Moreover, we observe that all real interest 
rate differentials follow a mean reverting behavior with nonlinear adjustment toward large but long-swing type smooth temporary changes around constant equilibrium values.

The rest of the paper is organized as follows. The next section presents a brief overview of the financial liberalization in East Asian countries. Section 3 briefly reviews the RIP theory, while Section 4 describes the econometric methodology we utilize. The data and the empirical results are then reported in Section 5, with concluding comments in Section 6.

\section{A Brief Overview of the Financial Liberalization in East Asian Countries}

Since the late 1970s, East Asian countries have taken crucial steps to liberalize their domestic financial systems by progressively removing restrictions on capital mobility. As stated by Phylaktis (1999) and Baharumshah et al. (2005), financial liberalization attempts in the East Asian countries followed almost the same two stage pattern, though timing and intensity of these stages differ across countries. As the first stage of the liberalization process, the countries gradually removed foreign exchange controls and the ceilings on lending and deposit rates. In this sense, Hong Kong, Malaysia and Singapore were among the first countries to liberalize their interest rate controls in the mid- and late-1970s. Subsequently, in the early 1980s, interest rates were fully deregulated in Indonesia and Philippines, while Thailand and South Korea removed the ceilings on their interest rates in the mid-1980s. A more gradual and systematic approach is followed in Japan so that interest rate liberalization started in 1979 was only completed in 1994. China, on the other hand, lags behind the other East Asian countries in terms of financial liberalization by following a substantially slow pace of liberalization process with small steps and no major changes in one big bang. As such, interest rate deregulations began in 1996, accelerated with the accession of China to the World Trade Organization (WTO) in 2001 and were almost completed by 2013.

Liberalization of the capital accounts and the stock markets were the second stage of the liberalization process with its main implications being removal of restrictions on borrowing abroad by banks and corporations, allowing foreign investors to hold domestic assets or vice versa and liberalizing the exchange rate market. In the late 1970s, most of the Asian countries including Japan, Korea, Hong Kong, Malaysia, Philippines, Singapore and Indonesia started to liberalize their capital accounts. For China, liberalization of the capital market was carried out in a controllable manner and continued during 2000s. Stock market liberalization, on the other hand, was completed for all countries except China by 1994. 
Hence, in the mid-1980s all countries except China were partially liberalized with deregulations being completed in at least one of three sectors including the capital account, the domestic financial sector, and the stock market (Kaminsky and Schmukler, 2003) ${ }^{2}$.

Following liberalization of financial markets, East Asian countries experienced a surge in foreign capital inflows during 1980s and early-1990s. To be more specific, capital inflows increased from an average of 1.4 percent of GDP over 1986-1990 to 6.7 percent over 19901996. As proposed by Radelet and Sachs (2000), the surge in capital inflows had its roots not only in wide-ranging financial deregulations implemented in East Asian countries but also in external factors like recessions in developed countries and low interest rates in the United States. Furthermore, high and continuing economic growth of these countries gave more confidence to foreign investors and boosted the volume and volatility of the short-term foreign capital. Consequently, East Asian financial institutions became more dependent on short term foreign capital and incurred a significant amount of external liquid liabilities that were not entirely backed by liquid assets, which in turn made them extremely vulnerable to speculative actions and a financial panic. Moreover, despite the concerns about potentially destabilizing effects of massive and sudden flows of foreign capital, governments gave special incentives that encouraged foreign borrowing. These massive short-term debts together with poor banking judgment, inadequate supervision of financial sector deregulations and the pegged exchange rate system dragged the region into the Asian crisis in 1997. The result was a wave of currency and banking crises, first affecting Thailand, then spreading to the rest of the region.

The 1997 Asian crisis revealed the importance of the strong domestic institutions and financial systems (Lee, 2002). Hence, in the aftermath of the crisis authorities revised their financial policies and imposed more systematic regulations to restructure and reform the banking sector, improve corporate governance, fiscal and currency management, facilitate regional integration and systematize liberalization of capital markets. Important progress was made in the years after the crisis so that the structural reforms have strengthen financial and real sectors of East Asian countries and boosted the financial market integration realized in these countries.

\footnotetext{
${ }^{2}$ See Kaminsky and Schmukler (2003) for a more detailed discussion of the country-specific liberalization policies.
} 


\section{Real Interest Rate Parity Theory}

The fulfillment of RIP theory rests on UIP and PPP hypotheses and Fisher equation. The UIP hypothesis states that the nominal interest rate differential should be equal to expected change in the exchange rate as:

$$
s_{t+1}^{e}-s_{t}^{e}=i_{t}-i_{t}^{*}
$$

where $i_{t}$ and $i_{t}^{*}$ stand for the domestic and foreign nominal interest rates, respectively, and $s_{t}^{e}$ represents the expected nominal exchange rate at time $t$. According to the PPP, on the other hand, the inflation differential should be offset by the change in the exchange rate so that one unit of the domestic currency can purchase the same bundle of goods and services in both countries over the same period. That is,

$$
s_{t+1}-s_{t}=\pi_{t+1}-\pi_{t+1}^{*}
$$

where $\pi_{t}$ and $\pi_{t}^{*}$ represent domestic and foreign inflation rates, respectively. Under the assumption that agents make their predictions using rational expectations, we have

$$
s_{t+1}^{e}-s_{t}^{e}=s_{t+1}-s_{t}+\varepsilon_{t}
$$

where $\varepsilon_{t}$ is a white-noise forecast error. Integrating equations (1), (2) and (3) yields:

$$
i_{t}-i_{t}^{*}=\pi_{t+1}-\pi_{t+1}^{*}+\varepsilon_{t}
$$

and it could be re-written as:

$$
i_{t}-\pi_{t+1}=i_{t}^{*}-\pi_{t+1}^{*}+\varepsilon_{t}
$$

Further, assuming that the Fisher equation is valid for both the home and foreign country, domestic and foreign real interest rates can be written as $r_{t}=i_{t}-\pi_{t+1}$ and $r_{t}^{*}=i_{t}^{*}-\pi_{t+1}^{*}$. Then, the equation (5) will imply the RIP condition as:

$$
r_{t}=r_{t}^{*}
$$

Finally, the real interest rate differentials, can be defined as:

$$
r i d s_{t}=r_{t}-r_{t}^{*}=\varepsilon_{t}
$$

In practice, Equation (7) suggests that, if UIP, PPP and rational expectations hold, rids are expected to follow a stationary $I(0)$ process with a strong tendency to turn back to its long-run zero mean level in response to any shocks. 


\section{Methodology}

This chapter describes the unit root tests of Christopoulos and Leon-Ledesma (2010) adopted to investigate the empirical validity of the RIP hypothesis for East Asian countries. The tests developed by Christopoulos and Leon-Ledesma (2010) account jointly for large but temporary smooth breaks and non-linear mean reversion in the series. In order to capture multiple smooth breaks of unknown form in the mean of the series, a Fourier function is employed, as in Becker et al. (2006). This implies that rids can be modelled as:

$$
\begin{aligned}
& \text { rids }_{t}=\delta(t)+v_{t} \\
& \delta(t)=\delta_{0}+\delta_{1} \sin \left(\frac{2 \pi k t}{T}\right)+\delta_{2} \cos \left(\frac{2 \pi k t}{T}\right)
\end{aligned}
$$

where $\delta(t)$ represents the time-varying deterministic component, $k$ is the number of frequencies, $t$ is a trend term, $T$ is the sample size, $\pi=3.1416$ and $u_{t}$ is the normally distributed disturbance term. The use of the Fourier function to approximate the unknown number of breaks of unknown form ensures that the breaks are captured endogenously and the forms of breaks do not have to be pre-determined so that the over-fitting of the series and the size distortion problems would be eliminated.

Once the baseline model in (8) is formed, the null of a unit root hypothesis is set as $H_{0}: v_{t}=\mu_{t}, \mu_{t}=\mu_{t-1}+h_{t}$ where $h_{t}$ is a zero-mean stationary process. To derive the corresponding test statistics, a three step procedure is proposed by Christopoulos and LeonLedesma (2010). The first step is estimating the model (8) and obtaining the residuals $\hat{v}_{t}$. Obviously, if the appropriate frequency $k$ was known, then it would be straightforward to estimate equation (8) and derive the residuals through OLS. However, the true number of frequencies is unknown. In this sense, Christopoulos and Leon-Ledesma (2010) suggest to employ a grid search procedure to find the appropriate $k$. More specifically, for each integer value of $k \in[1,5]$, equation (8) is estimated through OLS and the optimum frequency $\tilde{k}$ that yields the smallest residual sum of squares is selected. With the use of only integer numbers for $k$, it is ensured that smooth breaks are temporary due to starting and ending values of the Fourier function being same.

The next step is testing for a unit root in $\hat{v}_{t}$. As such, three different test regressions are constructed as follows: 


$$
\begin{gathered}
\Delta \hat{v}_{t}=\beta_{1} \hat{v}_{t-1}+\sum_{j=1}^{p} \alpha_{j} \Delta \hat{v}_{t-j}+\varepsilon_{t} \\
\Delta \hat{v}_{t}=\rho_{1} \hat{v}_{t-1}^{3}+\sum_{j=1}^{p} \alpha_{j} \Delta \hat{v}_{t-j}+\varepsilon_{t} \\
\Delta \hat{v}_{t}=\lambda_{1} \hat{v}_{t-1} F_{E}\left(\Delta \hat{v}_{t-1} ; \theta\right)+\sum_{j=1}^{p} \alpha_{j} \Delta \hat{v}_{t-j}+\varepsilon_{t} \\
F_{E}\left(\Delta \hat{v}_{t-1} ; \theta\right)=\left(1-\exp \left(-\theta \Delta \hat{v}_{t-1}^{2}\right)\right)
\end{gathered}
$$

where $p$ is the required number of lagged changes of $\Delta \hat{v}_{t}$ that ensures the white noise structure of the disturbance term $\varepsilon_{t}, F_{E}\left(\Delta \hat{v}_{t-1} ; \theta\right)$ symmetrically U-shaped exponential transition function bounded between zero and one, $\Delta \hat{v}_{t-1}$ is the transition variable and $\theta \geq 0$ is the slope parameter. Equation (9) is a standard ADF regression, where the unit root null hypothesis $H_{0}: \beta_{1}=0$ is tested against the alternative of stationarity by an ADF test named the Fourier-ADF (FADF) test. Obviously, under the alternative of stationarity, equation (9) assumes linear adjustment for rids. The next two equations, however, allow rids to follow a nonlinear stationary process.

More specifically, equation (10) corresponds to the modified version of the auxiliary test regression of Kapetanios et al. (2003), which is obtained by approximating the exponential transition function around the origin ${ }^{3}$. In this equation, the unit root null hypothesis of $\rho_{1}=0$ is tested against the alternative of $\rho_{1}<0$. With this form, rids display linear unit root behavior under the null hypothesis, while they follow a globally stationary ESTAR process under the alternative with significant mean reversion only if deviations of rids from their equilibrium values determined by the Fourier function are large. When deviations from their equilibrium are small, however, they follow a unit root behavior, possibly due to nonexistence of arbitrage opportunities. The null hypothesis is tested by the $t$ statistic:

$$
F-t_{N L}=\frac{\hat{\rho}_{1}}{\text { s.e. }\left(\hat{\rho}_{1}\right)}
$$

Equation (11), which is the modified version of the test regression developed by Kilıç (2011), is formed in a similar way to equation (10), with the differences being due to the choice of the transition variable and the setup of the null hypothesis. While in equation (10) it is assumed that the size of deviations from the equilibrium is decisive for emergence of

\footnotetext{
${ }^{3}$ See Kapetanios et al. (2003) for further details.
} 
arbitrage opportunities, in this new form it is assumed arbitrage opportunities, and hence, nonlinearities in rids are driven by the size of appreciations and depreciations in rids. This implies that only large appreciations or depreciations will force rids to adjust towards their equilibrium due to arbitrageurs engaging in profitable trading strategies. Then, to test the null of a unit root against a globally stationary ESTAR process, the null and alternative hypotheses are set as $H_{0}: \lambda_{1}=0$ and $H_{1}: \lambda_{1}<0$. However, since $\theta$ is unidentified under the null of a unit root, the test suffers from the nuisance parameter problem. To overcome this problem, the test statistic is formed as the minimum $t$-statistic on $\lambda_{1}=0$, which is derived over a fixed parameter space of $\theta$ values that are normalized by the sample standard deviation of the transition variable $\Delta \hat{v}_{t-1}$ as. Thus, the following $t$-statistic is used:

$$
F-\operatorname{Sup}-t_{i N}=\sup _{(\theta) \in \Theta}\left\{\frac{\hat{\lambda}_{1}(\gamma)}{\text { s.e. }\left(\hat{\lambda}_{1}(\gamma)\right)}\right\}_{\lambda_{1}=0}
$$

where $\Theta=[\underline{\gamma}, \bar{\gamma}]=\left[\frac{1}{100 s_{\Delta \hat{v}_{t-1}}}, \frac{100}{s_{\Delta \hat{v}_{t-1}}}\right], s_{\Delta \tilde{t}_{t-1}}$ is the sample standard deviation of $\Delta \hat{v}_{t-1}$.

The asymptotic distributions of all proposed $t$-statistics are non-standard and simulation of critical values is required. In this respect, Becker et al. (2006) showed that the asymptotic distribution of any type of unit root test that is based on a Fourier function, depends only on the frequency of the Fourier series. Given that, Christopoulos and LeonLedesma (2010) tabulated critical values for three tests through Monte Carlo simulations for each integer value of $k \in[1,5]$.

If stationarity of rids is ensured in the previous step, then one can continue with the final step of the testing procedure of Christopoulos and Leon-Ledesma (2010), which is testing for the presence of unknown smooth breaks. As such, the null hypothesis $H_{0}: \delta_{1}=\delta_{2}=0$ is tested against the alternative $H_{0}: \delta_{1}=\delta_{2} \neq 0$ in model (8) by using an $F$-statistic, $F(\tilde{k})$. The corresponding critical values simulated through Monte Carlo simulates are tabulated in Becker et al. (2006). As underlined by Christopoulos and Leon-Ledesma (2010), it is important to employ this $F$-test once stationarity of rids is confirmed due to its substantially low power when applied to nonstationary processes. Hence, a rejection of the null hypothesis in both steps two and three would imply that rids follow a mean reverting behavior toward some large but temporary changes in the mean of rids around a constant equilibrium. Moreover, if the rejection of the null in step two is obtained from $F-t_{N L}$ and/or $F-S u p-t_{i N}$ 
tests, while FADF fails to reject the null, then one can deduce that the observed mean reverting behavior follows a nonlinear pattern.

\section{Data and Empirical Results}

This paper investigates the empirical validity of the RIP hypothesis for East Asian countries including China, Hong Kong, South Korea, Indonesia, Malaysia, Philippines, Singapore and Thailand over the period 1984(1)-2016(11). As discussed before, the liberalization and deregulation processes in these countries are varied in terms of timing. Partial financial liberalization, however, was achieved in all these countries in 1984. That is why the year 1984 is selected as the starting date for all countries except for China and Hong Kong, for which the starting dates are set as 1987(1) and 1995(1), respectively, due to availability of the data. Moreover, Japan is chosen as the reference foreign country due to its being the major trading partner and contributor of direct investment and capital flows in the region (Baharumshah et al., 2005).

For calculation of real interest rates, we utilize nominal short-term interest rates. In fact, the choice of maturity of nominal interest rates is somewhat controversial in the empirical RIP literature. While some researchers including Baharumshah et al. (2005), Ferreira and Ledesma (2007), Holmes et al. (2011) and Liu et al. (2013) have used the shortrun nominal interest rates, the studies by Fountas and Wu (1999), Obstfeld and Taylor (2002) and Rapach and Weber (2004), amongst others, have employed long-term nominal interest rates. However, as indicated by Ferreira and Ledesma (2007) and Chang and Su (2015), investors usually prefer short-term investments to investments with long-term maturities due to the former being exposed to less interest rate risk. Moreover, the forecasting error associated with the composition of rids is also likely to increase as the maturity of holding an asset increases. To circumvent any substantial influence of risk premium and forecasting error, we prefer to use short-term nominal interest rates in our analysis. To be more specific, we use three-month deposit rates for Indonesia, Malaysia, Thailand, China and Japan, money market rates for South Korea, Philippines and Singapore and the three-month Treasury Bill Rate for Hong Kong. The choice of the interest rates is dictated by data availability.

Furthermore, being in line with most of the studies in the literature, we calculate $e x$ post real interest rates to test the RIP hypothesis. Although economic decisions by nature depend on the ex-ante real interest rates, under the assumption of rational expectations, the ex- 
post real interest rate will differ from the ex-ante real interest rate by a white noise forecast error term, as shown in Equation (3). For that reason, as proposed by Moosa and Bahatti (1996), stationarity of the ex-post real interest rate will imply the ex-ante rate being constant over time. Moreover, even without the assumption of rational expectations, studies including Fountas and $\mathrm{Wu}$ (1999), Camarero and Carrion-i-Silvestre (2010), Bagdatoglou and Kontonikas (2011) and Chang and Su (2015), show that empirical results do not exhibit substantial differences with respect to the method used to form real interest rates. Hence, under the assumption of rational expectations, we calculate the ex-post real interest rate at time $t$ for each country by subtracting actual inflation observed at time $t+3$ from the compounded quarterly interest rate at time $t$. In accordance with the existing RIP and UIP literatures, actual inflation is derived from the rate of growth of the Consumer Price Index (CPI), which is also transformed into a quarterly rate. All data are collected from the International Monetary Fund's International Financial Statistics (IFS) database and converted into natural logarithms.

Our empirical investigation starts with application of the conventional ADF and $\mathrm{Ng}$ and Perron (2001) unit root tests. The results together with the corresponding critical values are reported in Table 1. According to the results reported in the second column, the ADF test provides evidence for stationarity of rids for only three countries, Indonesia, Malaysia and Philippines. Next, we adopt the Ng and Perron (2001) unit root tests, which are modified versions of the standard unit root tests with better performance in terms of power and size distortions. As reported in the next four columns of Table 1, these modified tests, however, provide even less evidence for stationarity of rids compared to their traditional counterpart and fail to reject the null of nonstationarity for all cases except for China. As stated earlier, these conventional inferences might be misleading and seriously biased both when rids follow nonlinear structures and when they are confronted with structural breaks. Hence, to propose more reliable results, we proceed with the unit root tests of Christopoulos and Leon-Ledesma (2010), which account for both multiple smooth breaks and nonlinear mean reversion in rids.

As described in the previous section, Christopoulos and Leon-Ledesma (2010) proposes a three-step procedure to test the null of nonstationarity. Since there is no a priori information about the shape of the breaks, the first step is modelling smooth breaks in rids. As such, the Fourier model in (8) is estimated for each frequency $k=1, \ldots, 5$ and the optimal frequency $\tilde{k}$ that minimizes the sum of squared residuals is selected. As shown in the third column of Table 2, the optimal frequency is found to be 1 or 2 for all countries except China 
where a high frequency of 5 is observed. To illustrate the observed smooth structural breaks, we plot the time path of rids along with the estimated Fourier functions in Figure 1.

Table 1: Standard Linear Unit Root Tests Results

\begin{tabular}{lllllll}
\hline & Period & $A D F$ & $M Z_{\alpha}^{G L S}$ & $M Z_{t}^{G L S}$ & $M S B^{G L S}$ & $M P_{T}^{G L S}$ \\
\hline Indonesia & $1984(1)-2016(8)$ & $-3.47^{\mathrm{b}}$ & -4.88 & -1.52 & 0.31 & 5.12 \\
South Korea & $1984(1)-2016(8)$ & -2.01 & -2.85 & -1.04 & 0.36 & 8.21 \\
Malaysia & $1984(1)-2016(8)$ & $-3.34^{\mathrm{b}}$ & -7.92 & -1.97 & 0.25 & $3.14^{\mathrm{b}}$ \\
Philippines & $1984(1)-2016(8)$ & $-6.79^{\mathrm{a}}$ & -2.15 & -0.97 & 0.45 & 10.76 \\
Singapore & $1984(1)-2016(8)$ & -2.41 & -5.29 & -1.60 & 0.30 & 4.71 \\
Thailand & $1984(1)-2016(8)$ & -2.51 & -0.69 & -0.43 & 0.63 & 22.67 \\
Hong Kong & $1995(1)-2016(8)$ & -1.38 & -1.82 & -0.92 & 0.50 & 12.98 \\
China & $1987(1)-2016(8)$ & -2.58 & $-12.45^{\mathrm{b}}$ & $-2.49^{\mathrm{b}}$ & $0.20^{\mathrm{b}}$ & $1.98^{\mathrm{b}}$ \\
\hline Critical Values & & & & & & \\
\hline \multicolumn{1}{c}{$1 \%$} & & -3.47 & -13.80 & -2.58 & 0.17 & 1.78 \\
\multicolumn{1}{c}{$5 \%$} & & -2.87 & -8.10 & -1.98 & 0.23 & 3.17 \\
\hline
\end{tabular}

Notes: The lag order for $\mathrm{ADF}$ and $\mathrm{Ng}$ and Perron (2001) unit root tests are chosen using the modified AIC (MAIC) with a maximum autoregressive order of 12 as suggested by $\mathrm{Ng}$ and Perron (2001). ${ }^{\mathrm{a}}$ and ${ }^{\mathrm{b}}$ denote rejection of the null hypothesis of a unit root at 1 percent and 5 percent significance levels, respectively.

Table 2: Unit Root Test Results Based on Fourier Function

\begin{tabular}{lllllll}
\hline & Period & $\tilde{k}$ & $F(\tilde{k})$ & $F D A F$ & $F-t_{N L}$ & $F-S u p-t_{i N}$ \\
\hline & & & & & & \\
Indonesia & $1984(1)-2016(8)$ & 1 & $39.786^{\mathrm{a}}$ & $-5.722^{\mathrm{a}}$ & $-3.881^{\mathrm{b}}$ & $-5.449^{\mathrm{a}}$ \\
South Korea & $1984(1)-2016(8)$ & 1 & $230.143^{\mathrm{a}}$ & -3.577 & -2.091 & $-3.909^{\mathrm{b}}$ \\
Malaysia & $1984(1)-2016(8)$ & 1 & $46.343^{\mathrm{a}}$ & -3.757 & -3.191 & $-4.904^{\mathrm{a}}$ \\
Philippines & $1984(1)-2016(8)$ & 1 & $42.219^{\mathrm{a}}$ & $-6.556^{\mathrm{a}}$ & $-5.462^{\mathrm{a}}$ & $-7.282^{\mathrm{a}}$ \\
Singapore & $1984(1)-2016(8)$ & 2 & $81.409^{\mathrm{a}}$ & -2.566 & -3.063 & $-3.409^{\mathrm{b}}$ \\
Thailand & $1984(1)-2016(8)$ & 1 & $249.702^{\mathrm{a}}$ & $-3.929^{\mathrm{b}}$ & -2.982 & $-3.872^{\mathrm{b}}$ \\
Hong Kong & $1995(1)-2016(8)$ & 1 & $341.253^{\mathrm{a}}$ & -2.762 & -3.467 & $-4.946^{\mathrm{a}}$ \\
China & $1987(1)-2016(8)$ & 5 & $63.133^{\mathrm{a}}$ & -2.397 & $-3.656^{\mathrm{a}}$ & $-3.463^{\mathrm{b}}$ \\
\hline
\end{tabular}

Notes: In all tests, the augmentation order is chosen according to AIC with a maximum autoregressive order of 12. The critical values for the unit root tests $F D A F, F-t_{N L}$ and $F-S u p-t_{i N}$ depend on the frequency $\tilde{k}$ of the Fourier series and they are taken from Tables 1-3 of Christopoulos and León-Ledesma (2010). The critical values for the $F$-test $F(\tilde{k})$ are obtained from Table 1 of Becker et al. (2006). ${ }^{\mathrm{a}}$ and ${ }^{\mathrm{b}}$ denote rejection of the null hypothesis of a unit root at 1 percent and 5 percent significance levels, respectively. 


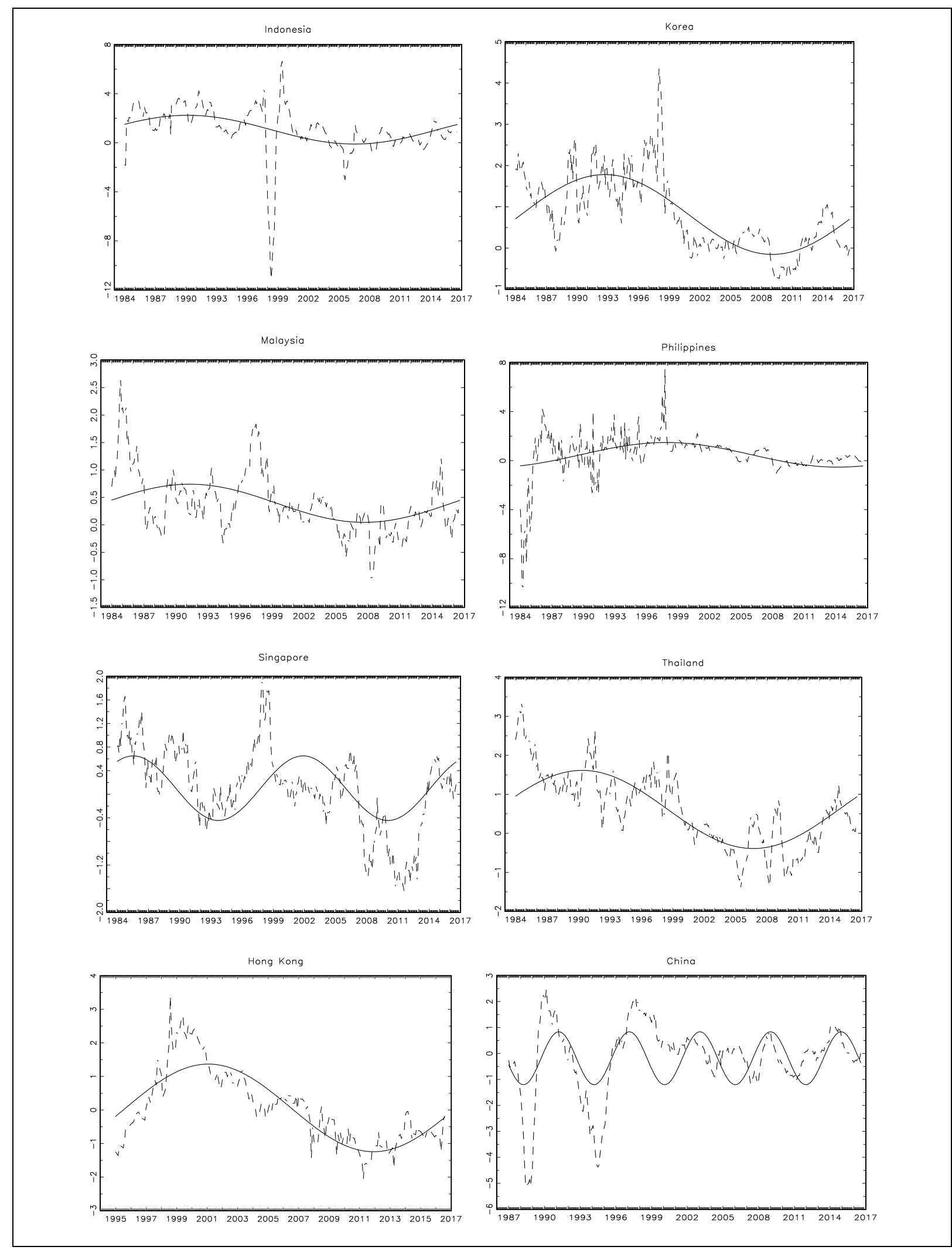

Figure 1: Real Interest Rate Differentials with Fitted Fourier Functions

It appears from the Figure that all Fourier approximations are reasonable and support the notion of long swings in rids. The effect of the Asian Crisis in 1997-1998 can be clearly 
seen for almost all of the countries in our sample. Among them, however, Indonesia appears to be hardest hit by the crisis. Before the crisis, Indonesian economy seemed to enjoy with moderate inflation and interest rates and a relatively stable exchange rate. In reality, however, it was quite vulnerable to external shocks due to fast and uncontrolled financial liberalization that resulted in massive capital inflows, large external debts and high volatility of speculative actions. Hence, following the onset of the crisis, Indonesian economy suffered from rapid currency devaluation, large scale withdrawal of foreign private capital, skyrocketed nominal interest rates and hyperinflation, which subsequently resulted in a dramatic fall observed in Indonesian rids during 1997-1998. For all other countries the effect of the Asian crisis on rids appears to be relatively less destructive. The downside effect of the 2008 financial global crisis, on the other hand, seems to be substantial in all rids, with the peak of real interest rate depreciation period varying across countries between 2008 and 2011. Although for the great majority of the countries the Fourier waves follow approximately a similar pattern, China is an outstanding exception with extra frequency changes. This is possibly due to its ongoing, gradual and controlled financial liberalization program, which is completely different from the other countries in the region. We observe two crucial downturns in Chinese rids series in 1988 and 1994, which correspond to the years when inflation reached its peaks due to the failure of the central bank of China to conduct proper monetary policies. The other downturns coincide with the accession of China to the WTO in 2001, removal of geographical and numerical restrictions on foreign banks in 2006 and beginning of the interest rate liberalization in 2012.

As the second step of the testing procedure of Christopoulos and Leon-Ledesma (2010), three unit root tests are applied to the OLS residuals derived from the estimated Fourier functions and the results are presented in Table 2. In this sense, the first test is the Fourier ADF (FADF) test, which assumes smooth breaks but linear mean reversion in rids. It is obtained from the test regression (9) and the results are reported in the fourth column of Table 2. According to the results, the FADF test supports stationary inference of the standard ADF test for Indonesia and Philippines. Moreover, the test reveals further evidence for stationarity of rids for Thailand, though the stationarity evidence of the ADF test for Malaysia is not supported. Hence, compared to the standard ADF test, it seems that the FADF test reveals almost no further evidence for stationarity of rids, even though smooth breaks are explicitly accommodated. 
Next, $F-t_{N L}$ and $F-S u p-t_{i N}$ test statistics, which allow for both multiple smooth breaks and nonlinear mean reversion in rids, are derived from the test regressions (10) and (11) and reported in the fifth and sixth columns of Table 2. The results from the $F-t_{N L}$ test indicate that the null of nonstationarity of rids can be rejected for Indonesia, Philippines and China. Turning to the $F-S u p-t_{i N}$ test, however, it appears that the null of a unit root is rejected for all transition countries under consideration. These findings suggest that the empirical support for stationarity of rids and, hence, RIP increases when rids are characterized by a nonlinear stationary process around infrequent multiple temporary mean changes. However, it is crucial to capture the correct form of nonlinearity. By associating nonlinearity with the size of real interest rate appreciation or depreciation, the $F-\operatorname{Sup}-t_{i N}$ test appears to be decisive in uncovering evidence for RIP. This suggests that relatively large appreciations and depreciations in real interest rates are the driving forces for investors to engage in profitable arbitrage activities. Then, the poor evidence yielded by the $F-t_{N L}$ test might be due to, associating nonlinearity with the size of deviations from RIP and, thus, failing to capture the correct form of nonlinear mean reversion in rids.

To illustrate the observed nonlinearity in rids, we further plot the estimated transition functions from (11) against the transition variable $\Delta \hat{v}_{t-1}$ and report the plots in Figure 2. Overall the transition functions appear to be well defined in all cases. To be more specific, being consistent with a classical ESTAR model, all transition functions are symmetrically $U$ shaped around zero equilibrium level with approximately equal number of observations above and below the equilibrium level. Moreover, the rate of mean reversion of rids appears to be same regardless of whether there is a depreciation or an equal amount of appreciation in real interest rates. Regarding the speed of transition, on the other hand, a large speed of transition is observed for the cases of South Korea and Philippines, while it seems relatively slow for China. 


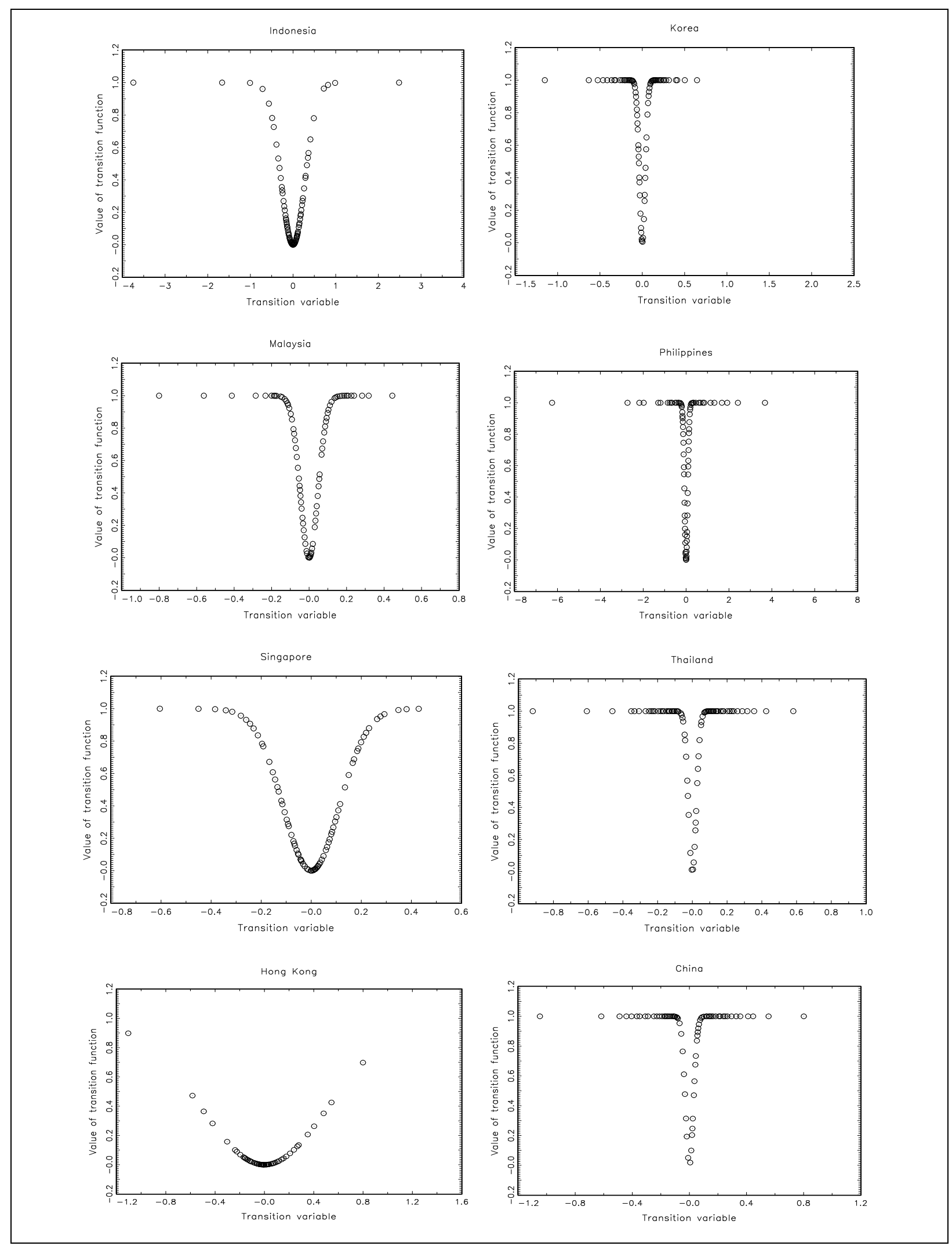

Figure 2: Scatter Plots of Estimated Transition Functions 
Once stationarity of all rids are ensured, we proceed with the final step of our analysis and test for significance of the smooth structural breaks through the $F(\tilde{k})$ test. As reported in the second column of Table 2, the results reveal substantially significant smooth breaks in all cases. This finding together with the observed nonlinearity imply that all rids are meanreverting around an infrequently smooth-breaking mean with mean reversion being faster when arbitrage opportunities arise due to large appreciations (depreciations) in real interest rates $^{4}$.

Overall, our findings reveal strong evidence confirming the RIP hypothesis for East Asian countries and carry important policy implications. First, the empirical validity of RIP suggests a high degree of financial integration between China, Hong Kong, South Korea, Indonesia, Malaysia, Philippines, Singapore and Thailand and Japan, which is in conformity with financial liberalization and capital market reforms witnessed by these countries. This finding could be also attributed to the Japanese leading role in the East Asian financial markets as being the major trading partner and contributor of direct investment and capital flows. Second, the observed mean reversion in rids implies that East Asian central banks have limited ability to affect real interest rates in the long-run through the interest rate channel alone, though some short-run influences may exist. Finally, it can be deduced from our results that these countries cannot benefit from any unlimited gains arising from arbitrage due to interest rate differentials disappearing across countries.

\section{Conclusion}

This study proposes an analysis for the empirical validity of RIP hypothesis for East Asian countries China, Hong Kong, South Korea, Indonesia, Malaysia, Philippines, Singapore and Thailand over the period of 1984(1) - 2016(8), which coincides with the deepening of financial liberalization and financial reforms, the 1997 Asian crisis and the 2008 financial

\footnotetext{
${ }^{4}$ We also performed the unit root test of Kilıç (2011), which does not take the smooth breaks into account but allows only for nonlinear mean reversion by forming the test regression (11) for rids. According to the results, available upon request, the null of nonstationarity cannot be rejected for South Korea, Singapore, China and Malaysia. This finding highlights the importance of accounting for nonlinearity and smooth breaks simultaneously and suggests that allowing for nonlinearity only offers a partial solution to non-rejection of nonstationarity of rids.
} 
global crisis. As known, the RIP theory requires stationarity of rids so that shocks to real interest rates die out quickly without allowing for unbounded gains arising from arbitrage. In numerous empirical studies, however, rids are found to display high persistency. These puzzling results lead an enormous and ever-growing empirical literature on RIP to emerge. Over recent years, it has been argued that the conflicting empirical evidences for RIP could be due to ignorance of the presence of structural breaks or potential nonlinear nature of real interest rate differentials. Consequently, some recent studies have utilized testing procedures that allow for structural breaks or nonlinear mean reversion in rids and proposed more supportive evidence for the validity of the RIP hypothesis. None of these studies, however, consider the possible interaction between existence of structural breaks and nonlinearity in rids but treat both problems separately.

In this sense, unlike the existing empirical RIP studies, our study employs the unit root tests developed by Christopoulos and Leon-Ledesma (2010) that not only account for the presence of multiple smooth breaks but also allow for nonlinearity in rids. Overall, our empirical findings reveal overwhelming evidences in favor of the RIP hypothesis for the whole transition countries in our sample. More specifically, it is found that all rids are meanreverting around an infrequently smooth-breaking mean, represented by a Fourier approximation. The mean reversion, however, appears to depend on the size of appreciations and depreciations in real interest rate differentials. That is, while large appreciations or depreciations lead rids to adjust towards their equilibrium, possibly due to the intervention of investors into the market to engage profitable trading strategies, they display high persistency otherwise. Furthermore, our finding that the unit root tests accounting either for structural breaks or for nonlinearity alone provide only a small extent of stationarity evidence, justifies that allowing for the correct form of nonlinearity and structural breaks simultaneously is crucial to eliminate the potential biases in statistical inference in the RIP framework.

\section{References}

Al-Awad, M. and Goodwin, B. K. (1998). Dynamic linkages among real interest rates in international capital markets. Journal of International Money and Finance, 17, 881-907.

Bagdatoglou, G. and Kontonikas, A. (2011). A New Test of the Real Interest Rate Parity Hypothesis: Bounds Approach and Structural Breaks. Review of International Eonomics, 19, 718-727. 
Baharumshah, A.Z., Chan, T.H., Fountas, S., (2005). A panel study on real interest rate parity in East Asian countries: Pre- and post-liberalization era. Global Finance Journal, 16, 69-85.

Baharumshah, A. Z., Liew, V. K-S. and Hamzah, N. A. (2008). Real Interest Rate Parity in the ASEAN-5 Countries: A Nonlinear Perspective. Applied Economics Letters, 15, 12, 955958.

Baharumshah, A. Z., Liew, V. K-S. and Haw, C. T. (2009). The Real Interest Rate Differential: International Evidence Based on Nonlinear Unit Root Tests. Bulletin of Economic Research, 61, 1, 83-94.

Baharumshah, A. Z., Liew, V. K-S. and Mittelhammer, R. (2010). Nonlinearities in RIRP: Evidence from OECD and Asian Dveleoping Economies. Global Economic Review, 39, 4, 351-364.

Baharumshah, A.Z., Soon, S.V. and Hamzah, N.A. (2013). Parity reversion in real interest rate in the Asian countries: Further evidence based on local-persistent model. Economic Modelling, 35, 634-642.

Becker, R., Enders, W. and Lee, J. (2006). A stationarity test in the presence of unknown number of smooth breaks. Journal of Time Series Analysis, 27, 381-409.

Camarero, M., Carrion-i-Silvestre, J. L. and Tamarit, C. (2010). Does Real Interest Rate Parity Hold for OECD Countries? New Evidence using Panel Stationarity Tests with Crosssection Dependence and Structural Breaks. Scottish Journal of Political Economy, 57, 5, 568590.

Chang, H.L., Liu, Y. and Su, C.W. (2012). Real Interest Rate Parity for East Asian Countries Based on China with Two Structural Breaks. International Review of Accounting, Banking and Finance, 4, 1-15.

Christopoulos, D.K. and Leon-Ledesma, M.A. (2010). Smooth breaks and non-linear mean reversion: Post-Bretton Woods real exchange rates. Journal of International Money and Finance, 29, 1076-1093.

Cooray, A. (2009). Is the Adjustment to Real Interest Rate Parity Asymmetric? Empirica, 36, 4, 407-418.

Cuestas, J. C. and Harrison, B. (2010). Further Evidence on the Real Interest Rate Parity Hypothesis in Central and East European Countries: Unit Roots and Nonlinearites. Emerging Markets Finance and Trade, 46, 6, 22-39.

Dumas, B. (1992). Dynamic Equilibrium and the Real Exchange Rate in a Spatially Separated World. Review of Financial Studies, 5,2, 153-180.

Ferreira, A. L. and Leon-Ledesma, M. A. (2007). Does the Real Interest Parity Hypothesis Hold? Evidence for Developed and Emerging Markets. Journal of International Money and Finance, 26, 3, 364-382. 
Frenkel, J.A. (1976). A Monetary Approach to the Exchange Rate: Doctrinal Aspects and Empirical Evidence. The Scandinavian Journal of Economics, 78, 2, 200-224.

Fountas, S. and Wu, J.L. (1999). Testing for real interest rate convergence in European countries. Scottish Journal of Political Economy, 46, 158-174.

Holmes, M.J. (2002). Does long-run real interest parity hold among EU countries? Some new panel data evidence. The Quarterly Review of Economics and Finance, 42, 4, 733-746.

Holmes, M.J. and Maghrebi, N. (2004). Asian real interest rates, nonlinear dynamics, and international parity. International Review of Economics and Finance, 13, 387-405.

Holmes, M.J., Otero, J. and Panagiotidis, T. (2011). Real interest parity: A note on Asian countries using panel stationarity tests. Journal of Asian Economics, 22, 550-557.

Jenkins, M. and Madzharova, P. (2008). Real interest rate convergence under the euro. Applied Economics Letters, 15, 6, 473-476.

Ji, P. I. and Kim, J. H. (2009). Real Interest Rate Linkages in the Pacific-Basin Region. International Review of Economics and Finance, 18, 3, 440-448.

Kaminsky, G.L. and Schmukler, S.L. (2003). Short-Run Pain, Long-Run Gain: The Effects of Financial Liberalization. IMF Working Paper, 3, 34.

Kapetanios, G. and Shin, Y. and Snell, A. (2003). Testing for a unit root in the nonlinear STAR framework. Journal of Econometrics, 112, 359-79.

Kılıç, R. (2011). Testing for unit root in a stationary ESTAR process. Econometric Reviews, 30(3), 274-302.

Lee, J. E. (2002). Real Interest Rates in Regional Economic Blocs. Applied Economics, 34, 7, 859-864.

Liu, Y., Chang, H.-L. and Su, C.-W. (2013). Do real interest rates converge across East Asian counturies based on China? Economic Modelling, 31, 467-473.

Lyons, R.K. (2001). New Perspective on FX Markets: Order-Flow Analysis. International Finance, 4, 2, 303-320.

Magonis, G. and Tsopanakis, A. (2013). Real Interest Rate Parity in OECD Countries: New Evidence from Time Series and Panel Cointegration Techniques. Applied Economics Letters, $20,5,476-479$.

Mancuso, A. J., Goodwin, B. K. and Grennes, T. J. (2003). Nonlinear Aspects of Capital Market Integration and Real Interest Rate Equalization. International Review of Economics and Finance, 12, 283-303.

Maveyraud-Tricoire, S. and Raus, P. (2009). RIP and the Shift Toward a Monetary Union: Looking for a 'Euro Effect' by a Structural Break Analysis with Panel Data. Journal of International Financial Markets, Institutions and Money, 19(2), 336-350. 
Moosa, I. A. and Bhatti, R. H. (1996). Does Europe Have an Integrated Capital Market? Evidence from Real Interest Parity Tests. Applied Economics Letters, 3, 8, 517-520.

Mussa, M. (1982). A Model of Exchange Rate Dynamics. Journal of Political Economy, 90, 1, 74-104.

Neely, C. and Rapach, D.E. (2008). Real interest rate persistence: evidence and implications. Federal Reserve Bank of St. Louis Working Paper, 018A.

Ng, S. and Perron, P. (2001). Lag length selection and the construction of unit root tests with good size and power. Econometrica, 69, 1519-1554.

Obstfeld, M., and Taylor, A.M. (2002). Globalization and capital markets. NBER Working Paper, 8846.

Papell, D.H. (2002). The great appreciation, the great depreciation, and the purchasing power parity hypothesis. Journal of International Economics, 57, 51-82.

Perron, P. (1989). The Great Crash, the Oil Price Shock and the Unit Root Hypothesis. Econometrica, 57, 1361-1401.

Phylaktis, K. (1999). Capital market integration in the Pasific Basin region: an impulse response analysis. Journal of International Money and Finance, 18, 2, 267-287.

Radelet, S. and Sachs, J. (2000). The Onset of East Asian Financial Crisis. Currency Crises. University of Chicago Press, 105-153.

Rapach, D.E. and Weber, C.E. (2004). Financial Variables and the Simulated Out-of-sample Forecastability of U.S. Output Growth Since 1985: An Encompassing Approach. Economic Inquiry, 42, 717-738.

Sarno, L., Valente, G. and Leon, H. (2006). Nonlinearity in Deviations from Uncovered Interest Parity: An Explanation of the Forward Bias Puzzle. Review of Finance, 10, 3, 443482.

Sarpota, M. C. (2009). An Empirical Analysis of RIRP for Industrialized Countries. Dissertation, University of Macedonia.

Sekioua, S. H. (2008). Real Interest Parity Over the 20th Century: New Evidence Based on Confidence Intervals for the Largest Root and the Half-Life. Journal of International Money and Finance, 27, 1, 76-101.

Sercu, P., Uppal, R. and van Hulle, J. (1995). The exchange rate in the presence of transactions costs: implications for tests of purchasing power parity. Journal of Finance, 50, 1309-1319.

Singh, M. and Banerjee, A. (2006). Testing Real Interest Parity in Emerging Markets. IMF Working Paper, 6, 249. 
Sirichand, K., Vivian, A. and Wohar, M.E. (2015). Examining real interest parity: Which component reverts quickest and in which regime? International Review of Financial Analysis, $39,72-83$.

Su, C.W., Shen, P.L., Chang, H.L. and Liu, L. (2012). Real interest rate parity in East Asian countries based on China with nonlinear threshold unit-root test. Applied Economics Letters, $19,15,1531-1536$.

Yamada, H. (2002). Real Interest Rate Equalization: Some Empirical Evidence from the Three Major World Financial Markets. Applied Economics, 34, 16, 2069-2073. 